\title{
PREVALENGE OF ANEMIA AND MORPHOLOGICAL VARIATION IN RBC AMONG COPD PATIENTS ADMITTED AT A TERTIARY HEALTH CARE GENTER, KATHMANDU,
}

\section{NEPAL}

Seerina Adhikari Manandhar, ${ }^{1}$ Tapas Pramanik, ${ }^{1}$ Krishna Chandra Devkota, ${ }^{2}$ Prem Prasad Panta ${ }^{3}$

${ }^{1}$ Department of Physiology and ${ }^{2}$ Department of Medicine, Nepal Medical College, Attarkhel, Gokarneshwor-8, Kathmandu and ${ }^{3}$ Associate Professor, Department of Biostatistics, Karnali Academy of Health Sciences, Jumla, Nepal

\section{ABSTRACT}

Many studies have depicted that anemia is one of the most common co-morbidity among Chronic Obstructive Pulmonary Disease (COPD) patients. Therefore, its correction in those patients is an important aspect of the treatment protocol. Our study was designed to explore the prevalence of anemia and morphological alteration, if any, in RBC among COPD patients. The study was conducted from November 2020 to June 2021 among the COPD patients admitted in the Medical ward of Nepal Medical College Teaching Hospital. If hemoglobin level was <13gm/dl in males and $<12 \mathrm{gm} / \mathrm{dl}$ in females and/or hematocrit level was $<39 \%$, the patient was considered anemic. Anemia was morphologically classified following standardized procedure with RBC indices as a reference. Among the COPD patients $(n=101), 40(39.6 \%)$ were anemic, out of which $21(52.5 \%)$ was normocytic normochromic, 10 (25\%) were microcytic hypochromic, 5 (12.5\%) were normocytic hypochromic, 3 (7.5\%) were microcytic normochromic and (2.5\%) was macrocytic hyperchromic. Anisocytosis was commonly noted (25.7\%) among the COPD patients with microcytosis (20.8\%) and macrocytosis (4.9\%) among them. Among the patients, $23.8 \%$ showed hypochromia while only $0.9 \%$ showed hyperchromia. Polycythemia was present in $24(23.8 \%)$ of them. Inflammatory mediators and cytokines in COPD causes a compromised response of marrow cells to erythropoietin and shortens the survival of red blood cells.

\section{KEYWORDS}

Anemia, COPD, Hepcidin

Received on: August 03, 2021

Accepted for publication: November 04, 2021

\section{CORRESPONDING AUTHOR}

Dr. Seerina Adhikari Manandhar,

Assistant Professor,

Department of Physiology,

Nepal Medical College, Attarkhel,

Gokarneshwor-8, Kathmandu, Nepal

Email: seerina1978@gmail.com

Orcid No: https://orcid.org/0000-0003-2214-8738

DOI: https://doi.org/10.3126/nmcj.v23i4.42224 


\section{INTRODUCTION}

Chronic obstructive pulmonary disease (COPD) is a common disease with high global prevalence. It is associated with significant morbidity and mortality worldwide with comorbidities like cardiac diseases, lung cancer, osteoporosis, and depression causing a negative effect on the prognosis of this disease. Recently, anemia has been recognized as a frequent comorbidity in COPD patients and has gained importance, as treatment of co-morbidities of a main disease is an important component in the management of the disease. ${ }^{1}$ Co-morbidity of COPD denotes a disease, co-existing with it and may be the reason that may complicate the prognosis. ${ }^{2}$ COPD is characterized by poorly reversible airflow limitation that is usually progressive and associated with an abnormal inflammatory response of the lungs to noxious particles or gases. However, the effect of these noxious gases not only causes airway and lung inflammation but also systemic cellular and humoral inflammation and other systemic manifestations. ${ }^{3}$ Among the common comorbidities associated to COPD, many studies have attempted to explore the co-existence of anemia with this disease. In a study done by John et al, ${ }^{4}$ only $13 \%$ of 101 COPD cases, were recorded to be anemic. However, a study conducted in a larger group of COPD patients $(n=132424)$ recorded $21 \%$ of the study population as anemic patients ${ }^{5}$ and study done by Shorr et $\mathrm{al}^{6}$ in 2,404 COPD patients, recorded $33 \%$ anemia cases among them. Another study in acutely exacerbated COPD patients $(n=107)$ during admission revealed $43.9 \%$ as anemic. ${ }^{7}$ Furthermore, in another study, among 36 COPD cases, $18 \%$ were anemic, out of which $32(88.89 \%)$ patients were normocytic normochromic while the rest had normocytic hypochromic type of anemia. ${ }^{8}$ To study a comorbid condition that is so common in COPD patients, present study was targeted to explore the prevalence of anemia and the morphological variation of RBCs in COPD patients admitted in Nepal Medical College and Teaching Hospital (NMCTH), Kathmandu, Nepal.

\section{MATERIALS AND METHODS}

We studied 101 COPD patients admitted in medical ward of NMCTH from November 2020 to June 2021, after obtaining an informed consent from them. Before commencing the study, an ethical clearance was obtained from the Institutional Review Committee of Nepal Medical College (NMC-IRC). Patients admitted in the medical ward of NMCTH were included in this study. Patients with cancer, thyroid disease, severe liver disease, chronic kidney disease, chronic heart failure, rheumatoid arthritis, GI hemorrhage or blood loss due to any other cause and patients with a known vitamin B12 or folic acid deficiency were not enrolled. Those patients who didn't have efficient mental capacity to give consent were also excluded. Hemoglobin level of less than $13 \mathrm{gm} / \mathrm{dl}$ in males and $12 \mathrm{gm} / \mathrm{dl}$ in females was considered as anemia. ${ }^{9}$ Packed cell volume (Hematocrit), less than $39 \%$ was also considered to diagnose anemia and those more than 55\% were considered to have polycythemia. ${ }^{10}$ Anemia so detected was then morphologically classified with the help of RBC indices. Mean corpuscular volume (MCV) ranging 85-95fl was considered as normocytic anemia. MCV $<80 \mathrm{fl}$ was taken as microcytic anemia while $>96$ was considered macrocytic anemia. Low $\mathrm{MCH}(<25 \mathrm{pg})$ and MCHC (<30\%) indicated hypochromic anemia, while $\mathrm{MCH}(>32 \mathrm{pg})$ and $\mathrm{MCHC}(>34.5 \%)$ was considered as hyperchromic anemia. ${ }^{11}$ Data was collected and compiled in Microsoft Excel 2007 worksheet and statistical analysis was done using SPSS version 16. In order to have a clear perception and understanding of RBC morphology, peripheral smear was prepared from few patients. For this, sample was taken by blood gun finger prick method applying aseptic measures. Smears were then stained with Leishman's stain following the standard procedure ${ }^{12}$ and was examined under microscope.

Table 1: Prevalence of anemia and it's classification in accordance to its morphological variation noted among the anemic COPD patients

\begin{tabular}{|lcc|} 
Anemia & $\mathbf{n}$ & $\mathbf{\%}$ \\
\hline Present & 40 & 39.6 \\
Absent & 61 & 60.4 \\
\hline Total & $\mathbf{1 0 1}$ & $\mathbf{1 0 0 . 0}$ \\
\hline
\end{tabular}

Type of anemia $(n=40)$

\begin{tabular}{lcc|}
\hline Microcytic Hypochromic (MH) & 10 & 25 \\
Microcytic Normochromic (MN) & 3 & 7.5 \\
Normocytic Hypochromic (NH) & 5 & 12.5 \\
Normocytic Normochromic (NN) & 21 & 52.5 \\
Macrocytic Hyperchromic & 1 & 2.5 \\
\hline Total & $\mathbf{4 0}$ & $\mathbf{1 0 0}$ \\
\hline
\end{tabular}




\section{RESULTS}

Out of 101 patients, more than two third (70.3\%) were females. The age ranged from 28-91 years with mean of $68.15^{+-12.1}$ years with almost half of the patients of more than 70 years of age while least were from the age group less than 40 years. As depicted by Table 1, the prevalence of anemia was more than one third (39.6\%) among the study population. Among the anemic patients, 21 (52.5\%) were normocytic normochromic, 10 (25\%) were microcytic hypochromic, 5 (12.5\%) were normocytic hypochromic, 3 (7.5\%) were microcytic normochromic and 1 (2.5\%) was macrocytic hyperchromic.

\begin{tabular}{|lcc|}
$\begin{array}{c}\text { Table 2: Prevalence of anisocytosis } \\
\text { (microcytosis and macrocytosis), } \\
\text { hyperchromia, hyperchromia and } \\
\text { polycythemia among the COPD subjects } \\
\text { (n=101). }\end{array}$ \\
\hline Variables & $\mathbf{n}$ & $\mathbf{\%}$ \\
\hline Anisocytosis & 26 & 25.7 \\
Microcytosis & 21 & 20.8 \\
Macrocytosis & 5 & 4.9 \\
Hypochromia & 24 & 23.8 \\
Hyperchromia & 1 & 0.9 \\
Polycythemia & 24 & 23.8 \\
\hline
\end{tabular}

Anemia was significantly associated with microcytic (Chi square value $=5.5, \mathrm{P}=0.019$ ) and hypochromic (chi square value $=6.89, \mathrm{P}=0.009$ ) changes in RBC morphology $(\mathrm{P}<0.01)$ (Table 3). Fig. 1 shows anisocytosis, microcytosis and hypochromia of RBCs in the smear obtained from COPD patient.

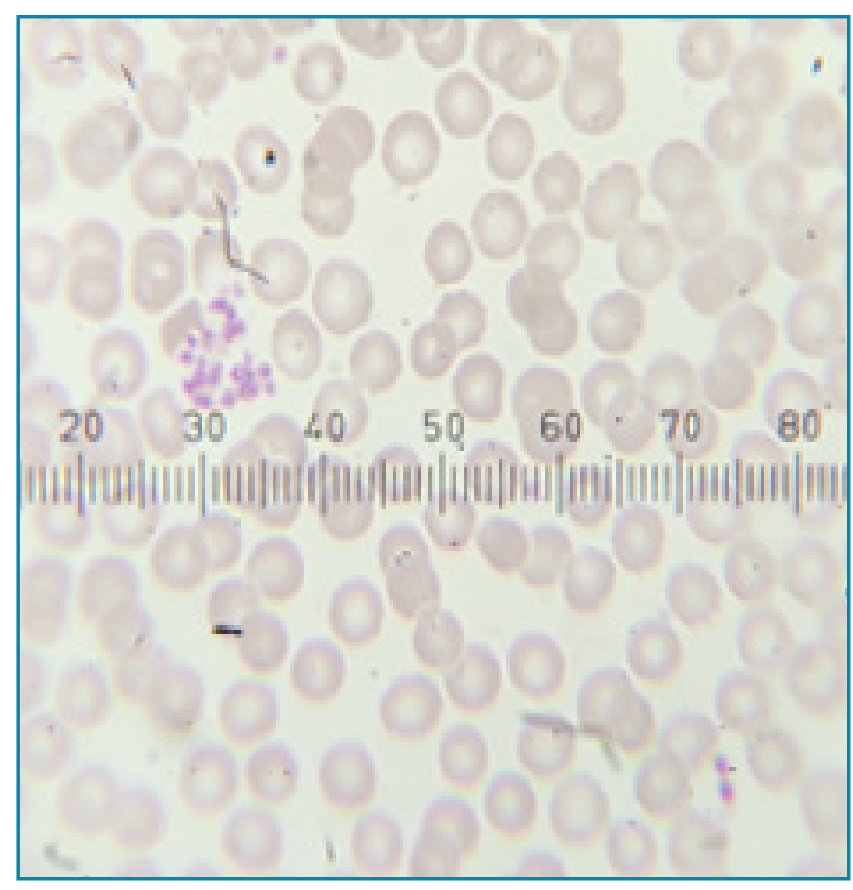

Fig. 1: Microphotograph showing anisocytosis, microcytosis and hypochromia of RBCs in the smear obtained from COPD patient.

Table 3: Association of anemia with different variable related to RBC morphology and its hemoglobin content.

\begin{tabular}{|c|c|c|c|c|}
\hline \multirow{2}{*}{$\begin{array}{l}\mathrm{n}=101 \\
\mathrm{RBC} \text { morphology, Hypochromia } \\
\text { and Hyperchromia }\end{array}$} & \multicolumn{2}{|c|}{ Anemia } & \multirow{2}{*}{$\begin{array}{c}\text { Chi square } \\
\text { value }\end{array}$} & \multirow[b]{2}{*}{$P$ value } \\
\hline & Present $(n=40)$ & Absent $(n=61)$ & & \\
\hline Anisocytosis & $14(35.0 \%)$ & $12(19.7 \%)$ & 2.96 & 0.085 \\
\hline Microcytosis & $13(32.5 \%)$ & $8(13.1 \%)$ & 5.5 & 0.019 \\
\hline Macrocytosis & $1(2.5 \%)$ & $4(6.5 \%)$ & 0.84 & 0.358 \\
\hline Hypochromia & $15(37.5 \%)$ & $9(14.8 \%)$ & 6.89 & 0.009 \\
\hline Hyperchromia & $1(2.5)$ & $3(4.9 \%)$ & & $1.0^{*}$ \\
\hline
\end{tabular}

* Fisher exact test

Table 2 highlights that anisocytosis (25.7\%) was a common finding among COPD patients irrespective of anemic status. Greater number $20.8 \%$ showed microcytosis and only $4.9 \%$ showed macrocytosis. Subjects with COPD also showed more cases of hypochromia (23.8\%) than hyperchromia $(0.9 \%)$. Polycythemia was also observed in many COPD patients (23.8\%).

\section{DISCUSSION}

More than one third of the COPD patients (39.6\%) were found to be anemic in the present study. John et $a l^{4}$ in similar number of COPD patients found only $13 \%$ as anemic. However, a study performed in a larger group of COPD patients $(n=132424)$ recorded $21 \%$ of the study 
population as anemic, ${ }^{5}$ while Shorr et $a l^{6}$ recorded 33\% anemia cases among 2404 COPD patients. Inflammatory cytokines produced during the disease process of COPD, specially IL-1 activates macrophages and thus enhances its phagocytic activity. However, in this process, the red blood cells also get attacked by the macrophages and even the newly formed RBC's are not spared leading to neocytolysis of these cells. Ultimately the RBCs are destroyed resulting in state of anemia. ${ }^{14}$

The present study noted that, among the anemic COPD patients, $52.5 \%$ were normocytic normochromic, $25 \%$ were microcytic hypochromic, $12.5 \%$ were normocytic hypochromic, $7.5 \%$ were microcytic normochromic and 1 (2.5\%) was macrocytic hyperchromic. A previous similar study also found that most of the COPD patients had normocytic normochromic anemia, while the rest had normocytic hypochromic type of anemia. ${ }^{8}$ Although anisocytosis was a common finding in COPD cases (25.7\%), more than half of the COPD subjects who were anemic had normocytic normochromic anemia (52.5\%). The factors necessary for erythropoiesis as well as the hepcidin concentration in each individual suffering with COPD might vary and may not significantly decrease to an extent to bring about morphological changes in the RBCs in these cases.

Anisocytosis (25.7\%) was a common finding among the COPD patients irrespective of the anemic status. Greater number (20.8\%) showed microcytosis and as well as hypochromia (23.8\%). Microcytosis and hypochromia was found to have significant association with anemic COPD cases $(\mathrm{P}<0.01)$. Microcytosis can be explained by the fact that with worsening of the condition in COPD, there might be a blunted response of the marrow cells to erythropoietin due to systemic inflammatory burden. ${ }^{15}$ Apart from the effect in bone marrow, there might also be an impact on kidneys, thereby decreasing erythropoietin and production of RBCs. ${ }^{16}$

The higher production of hepcidin in response to chronic inflammation might help to explain the cases of hypochromia in COPD cases. The production of inflammatory cytokines such as like IL-6 in COPD, stimulates the hepatocytes to produce Hepcidin. ${ }^{17,18}$ Hepcidin reduces the delivery of iron to maturing erythrocytes in bone-marrow by reducing the level of iron in plasma firstly by inhibiting iron absorption through intestinal enterocytes and secondly, by inhibiting release of iron from macrocytes and hepatocytes in plasma. ${ }^{18}$
Decreased hepcidin leads to tissue iron overload, whereas hepcidin overproduction leads to hypoferremia and the anemia of inflammation. Ferroportin is an iron exporter present on the surface of absorptive enterocytes, macrophages, hepatocytes, and placental cells. Hepcidin binds with ferroportin after which ferroportin is internalized and degraded, leading to decreased export of cellular iron. ${ }^{19}$ This might be the reason of hypochromia in patients with COPD as iron is one of the important nutrient required for RBC production in the bone marrow. ${ }^{20}$

Although anemia was a common finding in the present study, we cannot overlook the fact that most of them did not present anemia. This might be because of the fact that, blunted response to erythropoietin in COPD is a temporary phenomenon, response of bone-marrow cells to erythropoietin becomes normal when acute inflammation subsides. ${ }^{21}$ On the other hand, the study also recorded $23.8 \%$ polycythemia among the COPD patients. Conventional concept of physiological compensatory mechanism explains that hypoxemia caused by COPD increases the production of erythropoietin from the renal proximal convoluted tubular cells that decreases the rate of apoptosis of RBC stem cells, increases their survival and ultimately augments the rate of erythropoiesis leading to polycythemia. ${ }^{13}$ However, polycythemia is less evident condition in COPD patients due to rigorous correction of hypoxemia by domiciliary long term oxygen therapy. ${ }^{14}$ Hence, anemia and or altered morphology of RBC is a common comorbid condition faced by the clinicians in patients with COPD. Treatment protocols to alleviate these comorbidities along with the primary disease is an essential approach for treatment of the patient. A more elaborate and extensive study will definitely help to reach a more concrete conclusion.

\section{Conflict of interest: None}

Source of research fund: None

\section{REFERENCES}

1. Sarkar M, Rajta PN, Khatana J. Anemia in chronic obstructive pulmonary disease: prevalence, pathogenesis and potential impact. Lung India 2015; 32; 142-51.

2. Decramer M, Rennard S, Troosters T et al. COPD as a lung disease with systemic consecuences clinical impact, mechanisms and potential for early interventions. COPD 2008; 5: 235-56. 
3. Fabbri LM, Rabe KF. From COPD to chronic systemic inflammatory syndrome? Lancet 2007; 370: 797-9.

4. John M, Hoernig S, Doehner W et al. Anemia and inflammation in COPD. Chest 2005; 127: 825-9.

5. Halpern MT, Zilberberg MD, Schmier JK et al. Anemia, cost and mortality in chronic obstructive pulmonary disease. Cost Eff Resour Alloc 2006; 4: 17.

6. Shorr AF, Doyle J, Stern L et al. Anemia in chronic obstructive pulmonary disease: Epidemiology and economic implication. Curr Med Res Opin 2008; 24: 1123-30.

7. Silverberg DS, Mor R, Weu MT et al. Anemia and iron deficiency in COPD patients: prevalence and the effects of correction of the anemia with erythropoiesis stimulating agents and intravenous iron. BMC Pulm Med 2014; 14: 24.

8. Parveen S, Rangreze I, Ahamad SN et al. Prevalence of anemia in patients with COPD and its potential impact on morbidity of COPD patients. Int'l J Clin Med 2014; 5: 452-8.

9. Nutritional anemias: Report of a WHO scientific group. World Health Organ Tech Rep Ser 1968; 405: 5-37.

10. Chambellan A, ChailleuxE, Similowski $\mathrm{T}$ et al. Prognostic value of hematocrit in patients with severe COPD receiving long-term oxygen therapy. Chest 2005; 128: 1201-8.

11. Firkin F, Chesterman C, Penington D, Rush B, editors. deGruchy's Clinical Hematology in Medical Practice $5^{\text {th }}$ ed.Oxford: Blackwell Science;1989.

12. Duguid JP. Staining methods. In: Mackie and McCartney Practical Medical Microbiology. $14^{\text {th }}$ ed. New York, Churchill Livingstone 1996; 808.

13. Carroz KP. Anemia in COPD: should it be taken into consideration? Arch Bronchoneumol 2007; 43: $392-8$

14. Rice L, Alfrey CP, Driscoll T et al. Neocytolysis contributes to the anemia of renal disease. Am J Kidney Dis 1999; 33: 59- 62.

15. El-Korashy RI, Amin YM, Moussa HA et al. Study in the relationship of erythropoietin and chronic obstructive pulmonary disease. Egypt J Chest Dis Tuberc 2012; 61:53-7.

16. Nussbaumer-Ochsner Y, Rabe KF. Systemic manifestations of COPD. Chest 2011; 139: 165-17.

17. Nemeth E, Rivera S, Gabayan V et al. IL-6 mediates hypoferremia of inflammation by inducing the synthesis of iron regulatory hormone hepcidin. J Clin Invest 2004; 113: 1271-6.

18. Wrighting DM, Andrews NC. Interleukin-6 induces hepcidin expression through STAT-3. Blood 2006; 108: 3204-9.

19. Nemeth E, Tuttle MS, Powelson J et al. Hepcidin regulates cellular iron efflux by binding to ferroportin and inducing its internalization. Science 2004; 306: 2090-3.

20. Hall JE. Guyton and Hall Textbook of Medical Physiology. $12^{\text {th }}$ ed. Philadelphia: Elsevier 2011; 417-19.

21. Markoulaki D, Kostikas K, Papatheodorou G et al. Hemoglobin, erythropoietin and systemic inflammation in exacerbations of chronic obstructive pulmonary disease. Eur J Intern Med 2011; 22: 103-7. 